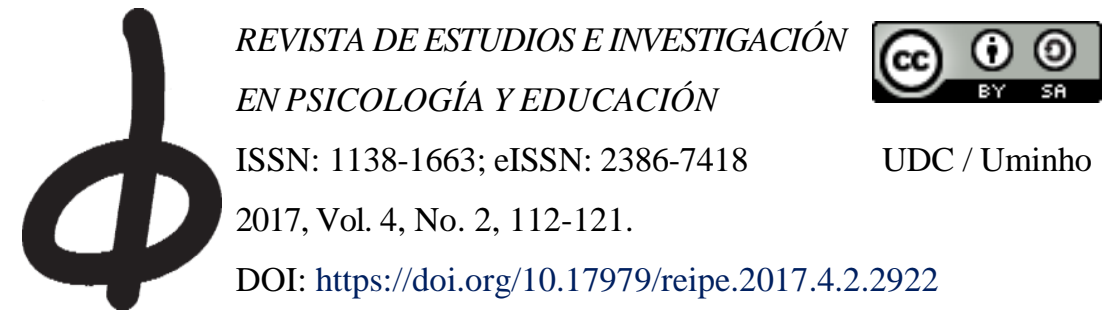

\section{Psychological intervention needs: validation of a survey with Portuguese university students}

\section{Necesidades de intervención psicológica: validación de una encuesta con estudiantes universitarios portugueses}

\author{
Joana Pinto(iD, Marco Martins \\ Universidade Católica Portuguesa
}

\begin{abstract}
This work presents and discusses the psychometric characteristics of the Portuguese version of The Survey of Student Needs (SSN), a self-report questionnaire that assesses psychological intervention needs. A total of 659 university students participated, $76.5 \%$ women, with a mean age of 21.96 years. The results of Exploratory Factor Analysis (EFA) report a factorial solution of three factors explaining $38.49 \%$ of the variance. Considering the internal consistency of this factorial structure, Cronbach's alpha values of .88 were found in factor 1, .81 in factor 2, and .84 in factor 3. The results of the Confirmatory Factor Analysis (CFA) suggest that the factorial solution proposed by the EFA presents better fit indices to the empirical data when compared to three alternative models $(\mathrm{X} 2 / \mathrm{df}=3.096, \mathrm{CFI}=.842$, GFI $=.851$, RMSEA $=.056, \mathrm{P}[\mathrm{rmsea} \leq .05]<.000)$. In conclusion, this study indicates that the SSN is a valid and reliable instrument applicable to the research and intervention contexts of this field.
\end{abstract}

Keywords: psychological needs; needs assessment; higher education; psychometrics

\section{Resumen}

Este trabajo presenta y analiza las características psicométricas de la versión en portugués de la Encuesta de Necesidades Estudiantiles (SSN), un cuestionario de autoinforme que evalúa las necesidades de intervención psicológica. Un total de 659 estudiantes universitarios participaron, $76.5 \%$ mujeres, con una edad media de 21.96 años. Los resultados de Análisis Factorial Exploratorio (AFE) informan una solución factorial de tres factores que explican el $38.49 \%$ de la varianza. Teniendo en cuenta la consistencia interna de esta estructura factorial, encontramos los valores alfa de Cronbach de .88 en el factor 1, .81 en el factor 2 y .84 en el factor 3 . Los resultados del Análisis Factorial Confirmatorio (CFA) sugieren que la solución factorial propuesta Por la EFA presenta mejores índices de ajuste a los datos empíricos en comparación con tres modelos alternativos ( $\mathrm{X}^{2}$ $/ \mathrm{df}=3.096, \mathrm{CFI}=.842, \mathrm{GFI}=.851, \mathrm{RMSEA}=.056, p[\mathrm{rmsea} \leq .05]<.000)$. En conclusión, este estudio indica que el SSN es un instrumento válido y confiable aplicable a los contextos de investigación e intervención en este campo.

Palabras clave: necesidades psicológicas; evaluación de las necesidades; educación universitaria; psicometría

Joana Pinto ${ }^{D}$ orcid.org/0000-0001-8151-7412, Faculdade de Ciências Humanas, Universidade Católica Portuguesa, Palma de Cima, 1649-023 Lisboa, Portugal.

Correspondence relating to this article: Joana Pinto - joanacarneiropinto@ fch.lisboa.ucp.pt 
The university is an important and privileged setting for assessing and intervening in mental health (Kessler, Berglund, Borges, Nock, and Wang, 2005). Most psychological disturbances arise in early adulthood, a time when a significant proportion of young adults enter university. This circumstance, which corresponds to a life transition, makes it important to rigorously assess university students in order to prevent, detect and treat any mental health problems that may occur (Zivin, Eisenberg, Gollust and Golberstein, 2009). In addition to the gains in terms of prevention and treatment of individual psychological suffering, these interventions are also beneficial in a broader sense, in educational, economic and social terms (Andrews, Hejdenberg, and Wilding, 2006).

The university experience is a time of transition, a process of continuous transformation, as individuals negotiate new academic and personal challenges (Rickinson, 1998). During this period, individuals face various developmental challenges that may include separation from the family, building their own social support networks, dealing with the rules and requirements of a new organization, establishing a career path, and building romantic relationships (Giovazolias, Leontopoulou and Triliva, 2010). This constitutes the socalled "emerging adulthood" (Arnet, 2000), a period in which people basically establish their identities. All of these changes potentially put the emotional well-being of the individual at risk and can trigger mental health problems (Roberts and Zelenyanski, 2002). Several studies have reported an increase in the psychological problems of university students over the last five years, specifically: learning difficulties (Gallagher, Sysko and Zhang, 2001), eating disorders (Fiates and Salles, 2001), problems with alcohol, and other illicit drugs (Wagner, Stempliuk, Zilberman, Barroso, and Andrade, 2007) and problems related to sexual abuse (Bertocci, Hirsch, Sommer and Williams, 1992). Kitzrow (2003) also highlights a variety of social and cultural problems that are increasingly affecting university students, such as divorce, family dysfunction, emotional instability, interpersonal difficulties, and the lack of parental and frustration tolerance.

The increasing differentiation of the university population also needs taking into account, especially regarding its characteristics, needs and family, economic, political and social origins (Silva and Nascimento, 2012). Compared with previous generations, current university students are more diversified, especially in terms of sex, age, and nationality (Pinto, Faria, Pinto, and Taveira, 2016). Therefore, this reality poses greater challenges to the psychological intervention services of higher education institutions.

Hence the importance of providing quality psychological counselling to students so they are able to meet academic requirements, engage in career exploration, and deal with personal and relationship issues (Giovazolias, et al., 2010). Recent research has proposed that students who benefit from counselling services in their institutions are then better prepared to deal with the social and academic contingencies that the university environment entails (Setiawan, 2006).

Researchers therefore agree on the need to regularly and accurately assess the needs of university students, whether to identify their concerns, develop group programs or to provide information to psychologists who undertake individual counselling (Nicholas 1995, 2002) but as well as for the purpose of maintaining a service that conforms to high quality standards (Gallagher et al., 1992). The evaluation of psychological intervention needs involves the process of carrying out a survey about the gaps or discrepancies identified between the actual situation and the desired situation, in terms of the concerns and needs for support among the target audience (Pinto, 2010; Rojo et al., 2002). This needs assessment essentially serves the following purposes: (i) to identify the real characteristics, expectations, motivations and fears, and client intervention needs (Gallagher, et al., 1992; Nicholas, 1995); (ii) to develop support systems that address the identified psychological intervention needs, i.e. designing, implementing, monitoring and evaluating "tailor-made" interventions (e.g., that focus on the development of new forms of intervention, in addition to individual intervention); (Herreras, 2002; Pérez Campanero, 1991); (iii) to identify the priority needs that should be met by the intervention program, even in the face of multiple needs (Kaufman, 1997, cit. in Rojo et al., 2002), (iv) to train counsellors to assist clients with their specific needs and concerns (e.g., training, workshops, supervision, observation and discussion of cases) (Nicholas, 1995); and, (v) to access greater investment, that is, more human, material and financial resources, from the institutions / contexts in which psychological interventions will occur (Barr and Cuyjet, 1991, cit. in Rojo et al., 2002; Tejedor, 1990).

In the university context, some studies that have sought, albeit in a non-systematic way, to evaluate the psychological intervention needs of their students - for example the University of Piraeus and the University of Crete, both in Greece (Giovazolias, et al., 2010), the Middle East Technical University (METU) in Turkey (Güneri, Aydin and Skovholt, 2003), the University of Western Cape, in South Africa (Nicholas, 1995, 2002; Van Schoor and Whitaker, 1988), the University of South Florida in the United States of America and also two public universities in Nigeria (Kenny, Aluede and McEachern, 2009). One important aspect in the assessment of needs and the subsequent founding and functioning of higher education psychological intervention services concerns the need for their full validation alongside validated psychometric instruments able to effectively assess the intervention needs experienced by students. The majority of these studies adopt questionnaires, semi-structured interviews or focus 
groups as their main methods of collecting data on the perceptions, preferences, expectations, and intervention needs of university students.

Regarding the application of quantitative methodologies, it is importante, for example, highlight the following studies: that developed by Arco, Fernandez, Hellborn and Lopez (2005), with 125 students from the University of Granada, in Spain that applied the Psychopedagogic Information Protocol (PIP), a checklist consisting of 80 items that cover a range of symptoms for which students seek counselling, organized into five categories: demographic, academic, psychological, interpersonal and vocational-professional. A study of South African students, developed between 1993 and 1994, details in the work by Nicholas (1995) administered a 42 item Survey of Student Needs (SSN; Gallagher et al, 1992) in order to evaluate the personal, career, and learning needs, on a 4-point Likert scale ("high", "moderate", "slight" and "no need"). In addition, the work by Voitkäne, Miezite, Rascevska, and Vanags (2006), including 313 college students, adopted the University of Latvia adaptation of the Students Needs Survey (Gallagher et al., 1992) consisting of 20 of the original items, organized into five factors, with four items composing each factor: Self-regulation; Study competencies; Self-confidence issues; Interpersonal communication problems and Somatic concerns. The article by Güneri, Aydin and Skovholt (2003), developed with students from the Middle East Technical University in Turkey, used the Student Needs Assessment Survey (SNAS; Loeffler, Haynes, Rengel, Volk and Wilkin, 1984). The Turkish version contains 70 items, organized into eight factors (academic concerns, interpersonal concerns, career planning, social interaction, cultural concerns, financial concerns, family concerns, and chemical use), on a 5-point Likert scale, ranging from "Not a concern" to "very much a concern" response format. In 2009, Kenny, Aluede, and McEachern (2009) applied the same instrument to 135 students, including 75 from a US public university in South Florida and 60 from two public universities in Nigeria. However, this instrument consisted of 64 statements, organized into twelve subscales: financial, career, academic, social, family, relationship, personality, depression, self-concern, drugs, gender and disability.

Following the review of these and other studies (e.g., Hinderaker, 2013), it may be verifyed that most researchers have developed their own instruments for data collection, according to their needs and in consideration of the characteristics of the intervention context and target audience. These instruments consist essentially of checklists where participants then either indicate the presence or absence of certain intervention needs or adopt Likert-type scales where participants indicate the frequency / intensity with which they experience a particular need. On the other hand, in addition to the great diversity of instruments available for assessing intervention needs in university students, there also seems to be strong concern over their psychometric robustness. The same instruments are on occasion deployed in cross-cultural research or, alternatively, systematically applied in various cultural groups in different countries, such as the SNAS and the SSN, which are two of the most widely disseminated instruments in international terms.

This study aims to contribute to this research line by analysing the psychometric properties of the Portuguese version of the Survey of Student Needs (SSN; Gallagher, Colin, and Kelleher, 1992; Pinto, 2010), a self-report questionnaire for identifying any psychological intervention needs in a sample of Portuguese university students. For this purpose, exploratory factorial analysis procedures served to derive the factorial solution that best represents, for this sample, the common factors and their relations with the manifested variables. Next a confirmatory factorial analysis was performed with the purpose of testing the quality of adjustment of four alternative models for the empirical data.

\section{Method}

\section{Participants}

This study contains a total of 659 university student participants, from twelve different instituions, all Portuguese nationals (north, centre and south Portugal), with 504 women $(76.5 \%)$. The ages ranged from 17 to 53 years $(M=21.96, S D=6.55)$. These students were enrolled on undergraduate $(n=495,75.1 \%)$, master's $(n=148$, $22.5 \%)$ or $\mathrm{PhD}$ programs $(n=1,0.2 \%)$ in $2015 / 2016$. About $78 \%(n=514)$ of students attended the course that was their first choice at the time of applying to higher education, with a current academic average of 13.96 values (scale $0-20$ values, $S D=1.58$, Min-Max $=10-20$ ). The definition of the number of participants in this study took into account the recommendations from Gorsush (2003) with recourse to at least 10 participants for each item that constitutes the instrument (in this case 44 items $\mathrm{x} 10$ participants $=440$ participants).

\section{Instrument}

The evaluation protocol was organized into two parts. In the first part, participants were asked to complete a brief sociodemographic record, consisting of eight items, related to a set of personal, academic and living condition variables. In the second part, participants completed The Survey of Student Needs (SSN; Gallagher, et al., 1992; Pinto, 2010). This is a self-report questionnaire that assesses personal, career and learning needs for higher education students. Its original version contains 42 items, organized into three areas: a) Personal Concerns (items 132); b) Career Concerns (items 33-36) and c) Learning Concerns (items 37-42). In this research version, the questionnaire consists of 44 items, with two items relating to illicit drug use and peer pressure to use illicit drugs (Personal Needs' subscale). The response to each item is 
reported on a four-point Likert scale, where 1 means "no need" and 4 means "high need". The scores of each subscale result from calculating the sum of the values assigned by the participants to each of their constituent items. Higher SSN scores indicate higher levels of personal, career and learning needs among college students.

\section{Procedures}

The evaluation protocol previously presented was inserted into an online platform (GoogleDocs), and disseminated through institutional emails (e.g., Catholic Unievrsity of Portugal) and social networks (e.g., Facebook). Data collection took place between January 2015 and July 2016 in accordance with all ethical and legal principles. The students were correspondingly presented with the study objective and an informed consent from that explained their participation was voluntary, the data collected would be anonymous, and they could interrupt the process of filling out the evaluation protocol at any time, without any type of loss. One of the researchers provided the email address should students wish to clarify any doubts about this study. Participants were not offered any rewards for their collaboration in the study.

\section{Data analysis}

Initially, the quality of the SSN items were analysed through the distribution of participant answers for each point on the response scale ( 1 to 4 of the Likert scale), with absolute and relative frequency measures, as well as through the central tendency and dispersion measures in addition to the calculation of the indices of asymmetry and kurtosis. Correlations were also calculated between the values assigned to each item and the total value for the set of items, that is, item-total correlations, and Cronbach's alpha coefficient without the item.

Then, to test the validity of the construct, exploratory factorial analyses were applied in order to extract the factors, and identify the items associated to each factor through analysis of their inter-correlations. The analytical procedures were performed on the main components with direct oblimin rotation (following the finding of high linear relationships between the variables; Pestana and Gageiro, 2005), with and without factor specification. This took into account the eingenvalues superior to the unit, and the factorial loads of items in the respective factors superior to .32 (Field, 2000). Finally, the internal consistency of the scale and the factors identified were ascertained through Cronbach's alpha, which analyses the congruence between each item and the remaining items of the questionnaire, assuming acceptable values as above .70 (Pestana and Gageiro, 2005).

In order to conclude, a confirmatory factorial analysis was developed and applied to evaluate the quality of adjustment to the empirical data of the four theoretical models derived from the AFE and the literature analysis within this scope and correspondingly applying the maximum likelihood estimation method. In order to interpret the quality of the adjustment, the following indices and respective reference criteria were deployed (Maroco, 2010): $X^{2}, X^{2} / d f$ ([2.0-5.0]), CFI (>.90), GFI (>.90), RMSEA (<.08), P[rmsea $\leq .05]$.

\section{Results}

\section{Descriptive statistics of items and subscales}

Table 1 presents the main descriptive results for the 44 items in the Portuguese version of SSN. Analysis reveals a dispersion in participant responses to the different responses available. However, analysis of the response averages for each item indicates a significant departure from the theoretical mean score of the response scale in favour of lower values. This situation also becomes evident in the analytical results for the participant response frequencies for each item, where there is a preference for the lowest points on the Likert scale, specifically the options 1 "no need" and 2 "reduced need", in items 9, 10, 12,14 to 19,21 to 34 and 44 .

Therefore, analysis of the coefficients of asymmetry and kurtosis indicates a distribution with characteristics of negative asymmetry and platykurtic, in particular for items 26 to 34. Analysis of the internal dispersion of the items performed through the interquartil range (IQ: 1 point) calculation proves present in most items except for numbers 29 to 34 . In turn, the results for the internal scale validity (corrected correlations for each item and the scale total) reports that the discriminative power of the items exceeds the critical score of .20 , ranging from .26 to .62 in all items except for item 34 (ritc $=.194$ ). Furthermore, the internal consistency of the items reflects the absence of homogeneity problems, with the Cronbach's alpha coefficients above the critical score of .70 in all items. The obtained results were 92 .

\section{Exploratory Factorial Analysis}

The Pearson's correlations between the SSN subscales were calculated, with positive correlations of .40 among all subscales, specifically between Personal Needs and Career Needs $(r=.443, p \leq .001)$, Personal Needs and Learning Needs $(r=.607, p \leq .001)$ and Career Needs and Learning Needs $(r=.444, p \leq .001)$.

Therefore, an exploratory factorial analysis with direct oblimin rotation while without a priori establishing the number of factors was advanced. Ten factors were found to explain $57.66 \%$ of the total variance in the items. However, this solution presented many problems, such as the reduced number of items for several factors, and the simultaneous saturation of several items by more than one factor. In this sense, and following the suggestion of the authors of the original questionnaire, new AFE analysis was performed, specifying three factors, extracted through the principal components method, with direct oblimin rotation, in an 
attempt to approach the organization of the original scale from Gallagher et al. (1992). This new factorial solution explained $36.42 \%$ of the total item variance. However, this also reported that through requiring factor saturation loadings in each factor of greater than .32, items 12, 20, 43 and 44 did not saturate in any factor. In this sense, an AFE of three factors was then chosen, excluding the four previously mentioned items.

Table 1.

The Survey of Student Needs: descriptive analysis

\begin{tabular}{|c|c|c|c|c|c|c|c|}
\hline Items - Needs & $\operatorname{Mean}(S D)$ & Median & $I Q$ & Skew & Kurt & $R I T C$ & $\alpha$ without item \\
\hline 1. Overcoming procrastination & $2.56(.97)$ & 3.00 & 1.00 & .196 & -.938 & .430 & .920 \\
\hline 2. Public anxiety speaking & $2.42(.99)$ & 2.00 & 1.00 & .036 & -1.050 & .365 & .921 \\
\hline 3. Increasing self-confidence & $2.56(.95)$ & 3.00 & 1.00 & -.092 & -.916 & 620 & .918 \\
\hline 4. Increasing motivation & $2.56(.92)$ & 3.00 & 1.00 & -.121 & -.812 & .564 & .918 \\
\hline 5. Eliminating self-defeating behaviours & $2.27(1.10)$ & 2.00 & 2.00 & .254 & -1.040 & .598 & .918 \\
\hline 6. Becoming more assertive & $2.31(.89)$ & 2.00 & 1.00 & .136 & -.744 & .535 & .919 \\
\hline 7. Fear of failure & $2.62(.94)$ & 3.00 & 1.00 & -.150 & -.847 & .508 & .919 \\
\hline 8. Controlling anxiety and nervousness & $2.81(.95)$ & 3.00 & 2.00 & -.235 & -.967 & .541 & .919 \\
\hline 9. Relationships with academic staff & $1.95(.91)$ & 2.00 & 2.00 & .598 & .095 & .508 & .919 \\
\hline 10. Coping with depression & $1.81(.97)$ & 2.00 & 1.00 & .931 & -.268 & .537 & .919 \\
\hline 11. Finding greater purpose in life & $2.10(.99)$ & 2.00 & 2.00 & .419 & -.95 & .528 & .919 \\
\hline 12. Meeting people to date & $1.83(.96)$ & 2.00 & 2.00 & .816 & -.507 & .306 & .921 \\
\hline 13. Overcoming shyness & $2.08(.97)$ & 2.00 & 2.00 & .458 & -.832 & .447 & .920 \\
\hline 14. Coping with loneliness & $1.70(.86)$ & 1.00 & 1.00 & .940 & -.135 & .512 & .919 \\
\hline 15. Discomfort in social situations & $1.92(.85)$ & 2.00 & 1.00 & .646 & -.220 & .560 & .919 \\
\hline 16. Recurrent headaches or stomachaches & $1.76(.93)$ & 1.00 & 1.00 & .995 & -.028 & .361 & .920 \\
\hline 17. Coping with a broken relationship & $1.67(.91)$ & 1.00 & 1.00 & 1.109 & .079 & .359 & .920 \\
\hline 18. Roles and expectations for men and women & $1.66(.79)$ & 1.00 & 1.00 & .919 & -.052 & .521 & .919 \\
\hline 19. Problems with controlling temper & $1.93(.92)$ & 2.00 & 2.00 & .628 & -.588 & .398 & .920 \\
\hline 20. Controlling weight & $2.14(1.05)$ & 2.00 & 2.00 & .397 & -1.109 & .309 & .921 \\
\hline 21. Adjustment to campus & $1.69(.79)$ & 2.00 & 1.00 & .868 & -.072 & .489 & .919 \\
\hline 22. Insomnia & $1.69(.91)$ & 1.00 & 1.00 & 1.132 & .255 & .370 & .920 \\
\hline 23. Concerns about sexual functioning & $1.47(.73)$ & 1.00 & 1.00 & .729 & 1.547 & .398 & .920 \\
\hline 24. Problems with parents & $1.73(.90)$ & 1.00 & 1.00 & 1.020 & .099 & .448 & .920 \\
\hline 25. Coping with prejudice & $1.45(.71)$ & 1.00 & 1.00 & .705 & 1.498 & .479 & .919 \\
\hline 26. Anxiety about AIDS & $1.41(.74)$ & 1.00 & 1.00 & 1.885 & 2.919 & .345 & .921 \\
\hline 27. Adjusting to culture norms & $1.44(.67)$ & 1.00 & 1.00 & 1.375 & 1.143 & .491 & .919 \\
\hline 28. Conflicts over values and morals & $1.58(.76)$ & 1.00 & 1.00 & 1.114 & .465 & .368 & .920 \\
\hline 29. Suicidal feelings & $1.19(.54)$ & 1.00 & 0.00 & 3.109 & 9.727 & .381 & .920 \\
\hline 30. Controlling drinking & $1.27(.58)$ & 1.00 & 0.00 & 2.115 & 3.657 & .303 & .921 \\
\hline 31. Controlling the use of drugs & $1.13(.43)$ & 1.00 & 0.00 & 3.671 & 13.991 & .260 & .921 \\
\hline 32. Concerns about sexual identity & $1.12(.42)$ & 1.00 & 0.00 & 4.186 & 19.308 & .264 & .921 \\
\hline 33. Peer pressure to drink to excess & $1.12(.42)$ & 1.00 & 0.00 & 3.914 & 16.643 & .251 & .921 \\
\hline 34. Peer pressure to use drugs & $1.06(.33)$ & 1.00 & 0.00 & 6.705 & 49.791 & .194 & .921 \\
\hline 35. Job search strategies & $2.71(.96)$ & 3.00 & 1.00 & -.376 & -.767 & .338 & .921 \\
\hline 36. Concern about career choice & $2.48(1.03)$ & 3.00 & 1.00 & -.032 & -1.149 & .401 & .920 \\
\hline 37. Understanding career interests, abilities & $2.41(.91)$ & 2.00 & 1.00 & .013 & -.828 & .536 & .919 \\
\hline 38. Selection of a major subject & $2.25(.94)$ & 2.00 & 2.00 & .166 & -.951 & .514 & .919 \\
\hline 39. Improving study skills & $2.63(.96)$ & 3.00 & 1.00 & -.205 & -.892 & .540 & .919 \\
\hline 40. Learning test taking strategies & $2.46(.98)$ & 2.00 & 1.00 & -.010 & -1.002 & .557 & .918 \\
\hline 41. Time Management skills & $2.71(.97)$ & 3.00 & 1.00 & -.277 & -.894 & .520 & .919 \\
\hline 42. Test anxiety & $2.58(1.03)$ & 3.00 & 1.00 & -.069 & -1.146 & .549 & .918 \\
\hline 43. Maths anxiety & $2.12(1.17)$ & 2.00 & 2.00 & .488 & -1.299 & .342 & .921 \\
\hline 44. Improving reading skills & $1.86(.93)$ & 2.00 & 2.00 & .694 & -.623 & .469 & .919 \\
\hline
\end{tabular}

The inter-correlation matrix tests, such as the KeyserMeyer-Olkin test $(K M O=.907)$, and the Bartlett test $\left(X^{2}\right.$ $=10105.277 ; d f=780 ; p \leq .001)$, presented suitable values. The exploratory factor structure of the SSN (Survey of Student Needs) consists of three factors with eingenvalues superior to 1 , accounting for $38.49 \%$ of total item variance. Table 2 presents the percentage of explained variance and the Cronbach's alpha result for each of the three factors, as well as their factorial weightings and the commonalities of the constituent items. Factor 1 presents an eigenvalue of 9.892, and explains $24.73 \%$ of the total variance. This consists of the items related to Self-Relationship Needs (items 2, 3, 4, 5, 6, 7, 8, 9, 10, 13, 14, 15, 16, 19, 21, 22, 29 and 42). Factor 2, in turn, presents an eigenvalue of 3.22 
and explains $8.05 \%$ of the total variance and contains the items related to Social Relationship/ Social Adaptation Needs (items 17, 18, 23, 24, 25, 26, 27, 28, 30, 31, 32, 33, $34)$. Furthermore, factor 3 presents an eigenvalue of 2.29 , and explains $5.72 \%$ of the total variance, consisting of items referring to Study and Work Needs (items 1, 11, 35, $36,37,38,39,40$ and 41).

Table 2.

The Survey of Student Needs: exploratory factorial analysis with rotation solution

\begin{tabular}{|c|c|c|c|c|}
\hline Items - Needs & Factor 1 & Factor 2 & Factor 3 & $h^{2}$ \\
\hline 3 & .772 & & & .595 \\
\hline 8 & .701 & & & .498 \\
\hline 5 & .675 & & & .518 \\
\hline 7 & .660 & & & .435 \\
\hline 10 & .648 & & & .459 \\
\hline 13 & .618 & & & .352 \\
\hline 15 & .586 & & & .415 \\
\hline 42 & .545 & & & .435 \\
\hline 14 & .531 & & & .392 \\
\hline 9 & .515 & & & .348 \\
\hline 6 & .500 & & & .379 \\
\hline 2 & .478 & & & .238 \\
\hline 16 & .476 & & & .216 \\
\hline 4 & .475 & & & .412 \\
\hline 29 & .453 & .316 & & .334 \\
\hline 22 & .401 & & & .214 \\
\hline 21 & .388 & & & .286 \\
\hline 19 & .363 & & & .217 \\
\hline 24 & .332 & .351 & & .301 \\
\hline 40 & & & .531 & .473 \\
\hline 18 & & .403 & & .372 \\
\hline 25 & & .481 & & .385 \\
\hline 41 & & & .535 & .436 \\
\hline 39 & & & .551 & .459 \\
\hline 1 & & & .381 & .270 \\
\hline 23 & & .439 & & .285 \\
\hline 11 & & & .441 & .363 \\
\hline 17 & & .334 & & .193 \\
\hline 36 & & & .769 & .545 \\
\hline 31 & & .714 & & .471 \\
\hline 27 & & .542 & & .424 \\
\hline 34 & & .663 & & .403 \\
\hline 38 & & & .777 & .614 \\
\hline 35 & & & .611 & .349 \\
\hline 33 & & .621 & & .366 \\
\hline 32 & & .516 & & .269 \\
\hline 30 & & .643 & & .401 \\
\hline 28 & & .527 & & .345 \\
\hline 26 & & .520 & & .306 \\
\hline 37 & & & .776 & .625 \\
\hline Eigenvalue & 9.892 & 3.218 & 2.286 & \\
\hline$\%$ of var. explained & 24.730 & 8.046 & 5.716 & \\
\hline Cronbach's alpha & .884 & .810 & .840 & \\
\hline
\end{tabular}

Note: Factor 1: Self-relations needs; Factor 2: Social relationships / social adaptation needs; Factor 3: Study and Work needs

Taking into account items 24 and 29 simultaneously saturate more than one factor, based on theoretical assumptions, Item 29 was distributed by factor 1 and item 24 by factor 2 . It is also worth noting that item 42 saturates in factor 1 according to the AFE performed, however, the original version of the instrument associates this item with Learning Needs.

The analysis reports how all the items return a greater correlation with the total of the factor to which they belong than with the other two factors to which they do not belong. These results indicate that the organization of the questionnaire (identified factors and items allocated to each factor), as identified in the AFE, is adequate and valid (Pestana and Gageiro, 2005).

Considering the internal consistency of this factorial structure, results above the critical .70 (Nunnally, 1978) were returned in the questionnaire as a whole $(\alpha=.919)$, as well as in all subscales, with Cronbach's alpha values of .88 in Factor 1, .81 in Factor 2, and .84 in Factor 3. This proves the absence of any homogeneity problems in participant responses to the items and the construct evaluated by the test.

\section{Confirmatory factorial analysis}

The degree of adjustment of the following four measurement models was then tested in accordance with the empirical data collected:

1. Original model of 42 items, organized into three areas: (a) Personal Needs (items 1-32); (b) Career Needs (items 33-36) and (c) Learning Needs (items 37-42), except for items 31 and 33, which were added to the Portuguese version;

2. Model of 44 items, organized into three areas: Personal Needs (items 1-34); (b) Career Needs (items 3538 ) and (c) Learning Needs (items 39-44), including items 31 and 33 that were added to the Portuguese version;

3. Model resulting from AFE, organized into three areas: (a) Self-relationship needs (items 2, 3, 4, 5, 6, 7, 8, $9,10,13,14,15,16,19,21,22,29$ and 42); (b) Social relationship/ social adaptation needs (items 17, 18, 23, 24, $25,26,27,28,30,31,32,33,34)$; and (c) Study and work needs (items 1, 11, 35, 36, 37, 38, 39, 40 and 41);

4. Model resulting from AFE, organized into three areas: (a) Self-relationship needs; (b) Social relationship/ social adaptation needs; and (c) Study and work needs with correlation between errors from the items: 30-31, 30-33, 31-34, 33-34, 36-38, 37-38, 36-39, 27-28, 10-29, 35-36, 11-36, 40, 42, 13-15, 8-42, 40-41, 9-11 and 2-13.

Table 3 presents the results obtained for the main evaluation indices for the quality of adjustment of each of the four theoretical SSN models to the empirical data collected. The findings indicate an unsatisfactory adjustment of the first three models in relation to the observed structural correlation. In each of these models, the $X^{2} / g l$ values, as well as the RMSEA values, fall within acceptable parameters. However, the values of the $C F I$ and GFI indexes are, in most of the models, unacceptable. In this sense, and following the indications of the analysis modification indexes, correlations were established 
between the errors of the previously indicated items, as these may prove indicative of causes common to the manifest variables, besides the latent variables explicitly defined in the model (Marôco, 2010, p.24).

Table 3.

Indexes of global adjustment of the theoretical models of the SSN to the empirical data

\begin{tabular}{|c|c|c|c|c|c|c|}
\hline Models & $X^{2}$ & $\mathrm{df}$ & $X^{2} / \mathrm{df}$ & CFI & GFI & RMSEA \\
\hline $\begin{array}{l}\text { Model 1: Original model of three correlated factors, proposed by } \\
\text { Gallagher et al. (1992) - } 42 \text { items }\end{array}$ & 3571.442 & 816 & 4.377 & .709 & .749 & $.072 * * *$ \\
\hline $\begin{array}{l}\text { Model 2: Original model of three correlated factors, proposed by } \\
\text { Gallagher and collaborators (1992) - } 42 \text { items }+2 \text { items (PT version) }\end{array}$ & 4276.700 & 899 & 4.757 & .668 & .713 & $.076 * * *$ \\
\hline $\begin{array}{l}\text { Model 3: Model of three correlated factors, resulting from AFE ( } 40 \\
\text { items) }\end{array}$ & 3591.372 & 737 & 4.873 & .701 & .757 & $.077 * * *$ \\
\hline $\begin{array}{l}\text { Model 4: Model of three correlated factors, resulting from AFE ( } 40 \\
\text { items) - With correlation between errors }\end{array}$ & 2223.242 & 718 & 3.096 & .842 & .851 & $.056^{* * *}$ \\
\hline
\end{tabular}

Model 4, resulting from the AFE, with three factors and correlations between the errors of some items, presents satisfactory levels of adequacy to the data $\left(X^{2} / d f=3.096\right.$, $C F I=.842, G F I=.851$, RMSEA $=.056$, P [rmsea $\leq .05]$ $<.000)$. The estimated regression coefficients are both high for all components and statistically significant $(p<.001)$.

Figure 1 presents the results for the standardized factor weightings and the individual reliability of each item in the correlated three factor model, resulting from the AFE (40 items), with correlations between some of the item errors.

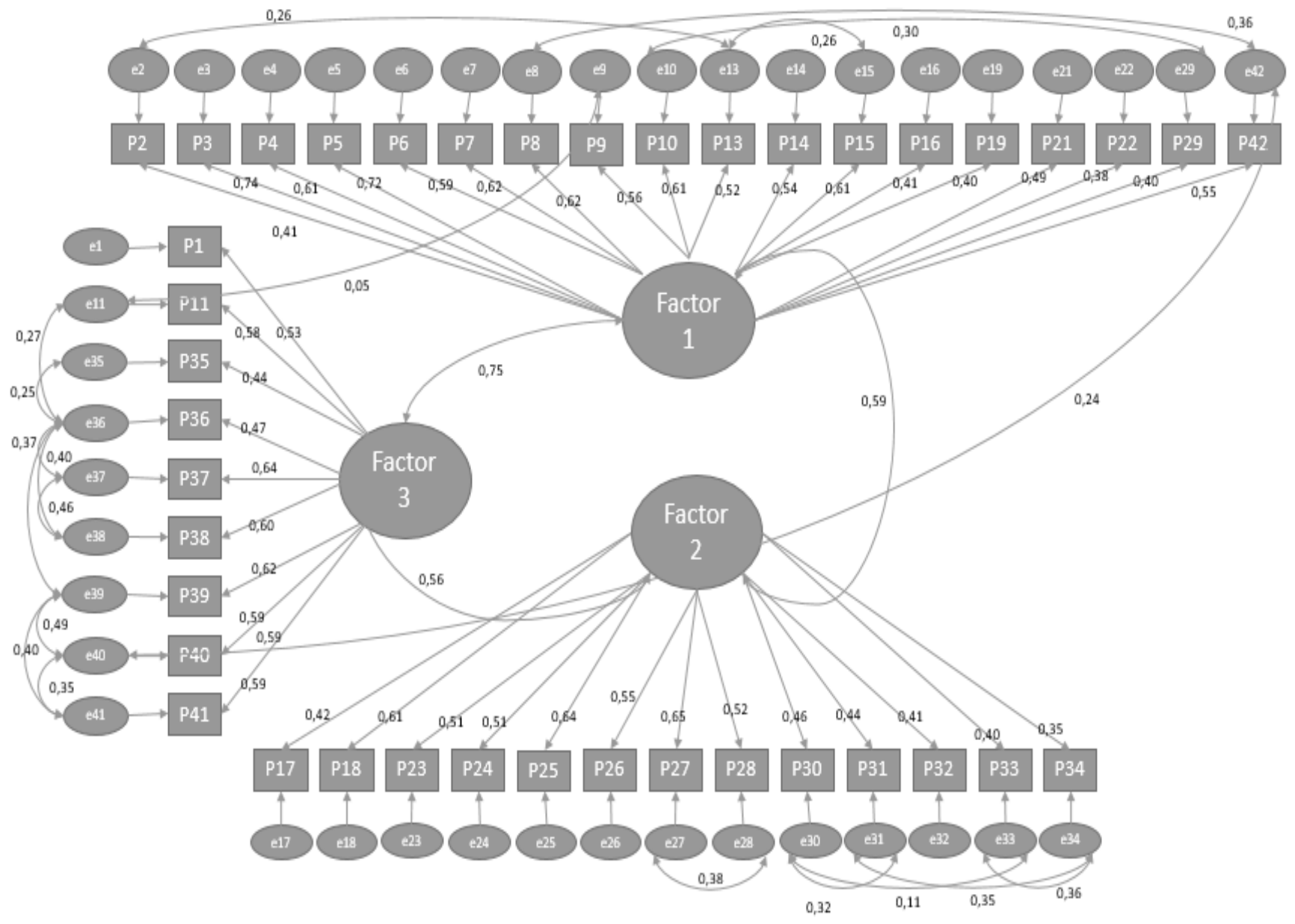

Figure 1. Model of The Survey of Student Needs, with three correlated factors 


\section{Discussion}

The present study sought to analyse the psychometric qualities of the Portuguese version of the SSN with a sample of university students. This is an innovative study as there are few previous publications on the sensitivity, validity and reliability of this instrument at the international level, although it has already served for study of North American student (Gallagher et al., 1992), South African Students (Nicholas, 1995, 2002), and Latvia student samples (Voitkāne, Miezīte, Rasčevska, and Vanags, 2006).

Firstly, it may be verified that this sample attained average item results lower than the mean score of the response scale across practically all items. Exceptions included items such as "increasing self-confidence", "increasing motivation", "fear of failure", "Controlling anxiety and nervousness", and "test anxiety", related to Self-Relation Needs; "overcoming procrastination", "improving study skills", "job search strategies", and "time management skills", related to Study and Work Needs. As with previous studies in Portugal (Pinto, et al, 2016), this sample expresses low support needs. These results are lower than those obtained by previous international studies, which found that the psychological intervention needs felt by students were generally higher (e.g., Gallagher et al., 1992; Hinderaker, 2003; Nicholas, 1995). However, there is a similarity between the concerns identified in this Portuguese sample and those obtained in the sample of North American students in the study by Gallagher et al. (1992), with particular emphasis on career and learning concerns as the most pressing problems (Schoor and Whittaker, 1988).

Next, results indicate that the most interpretable factorial solution comprises three factors, which explain $38.49 \%$ of the total construct variance. It is also important to should also note that although 3 factors were found, as indicated by the original authors, these factors are not the same. Specifically, in the manuscripts applying the SNS (e.g., Nicholas, 1995, 2002, 2003; Gallagher et al., 1992), factor 1 relates to Personal Needs and includes items 1-34, factor 2 relates to Career Needs and includes items 35-38, and factor 3 relates to Learning Needs and includes items 39-44. However, the AFE results in the Portuguese sample indicate that items $2,3,4,5,6,7,8,9,10,13,14,15,16$, 19, 21, 22, 29 and 42 correspond to Factor 1 - Selfrelationship Needs, items 17, 18, 23, 24, 25, 26, 27, 28, 30, $31,32,33$, and 34 correspond to factor 2 - Social relationships/ social adaptation Needs, and items 1, 11, 35, $36,37,38,39,40$ and 41 correspond to factor 3 - Study and Work Needs. This new organization seems to indicate an important distinction between the "self in relation to oneself" and the "self in relation to the other", already also encountered in previous studies (e.g., Arco, Ferrnandez, Hellborn, and Lopes, 2005). As an example, in the study by Arco et al. (2005), the instrument used for assessing University of Granada student needs -the Psychopedagogic
Information Protocol (PIP)- was organized into five dimensions, including the psychological and the interpersonal. The presence of three factors indicates how the Portuguese version of the SNS departs from similar instruments for assessing student counselling needs. However, the generality of the existing literature in this domain indicates academic, career, and personal/social needs as the most commonly identified constructs by assessments of counselling needs (Gysbers and Henderson, 2006; Nicholas, 2002, Tahhan and Eitah, 2002). It is also important to point out that item 42 "Test anxiety" is not interpreted by students in this sample as a concern within the scope of Study and Work Needs, but rather classified as a Self-Relationship need and as intrinsic to their personality traits.

Subsequently, the confirmatory factorial analysis results corroborate the quality of theoretical model 4 - resulting from the AFE, made up of three factors, but with errors in the mutually correlated items, - and its appropriateness to the empirical evidence and failing to support the remaining hypotheses related to the adjustment of the different alternative methods to this sample of Portuguese university students. This indicates, however, that there is a significant error percentage common to the different items even while almost always items within the same factor. Analysis of each of the correlations between these errors proves revealing of what each item activates in participants when responding. In comparison to these results, it is important to note how the study by Voitkāne, Miezite, and Vanags (2005; in Voitkāne, et al. 2006) proposed and developed the University of Latvia Adaptation of the Student Needs Survey (Galagher, et al., 1992), which consisted of studying first-year student adaptation at the University of Latvia and the 20 most typical concerns they reported at the beginning of their studies. Rotated component matrix analysis yielded five factors, with four items for each factor: Self- regulation; Study competencies; Selfconfidence issues; Interpersonal communication problems and Somatic concerns.

In conclusion, this study indicates that the $\mathrm{SSN}$ is a valid and reliable instrument applicable to the research and intervention contexts of this field. Considering the results presented previously, the 3 -factor model resulting from the AFE, with correlated errors, would seem the most appropriate for applying to the Portuguese university population. Thus, although this is only a first study for the validation of the SSN instrument for the Portuguese population, and some difficulties were inherent in the results obtained, this nevertheless seems a promising tool for psychologists working in counselling services for rigorously assessing the needs for support and psychological intervention in the different domains of life of university students, and consequently, for developing interventions that they recognize as pertinent. In the near future, there is a need to develop new studies that prove the theoretical three factor model deriving from this study, and 
alongside other alternative models, in new Portuguese higher education samples that display a greater range of diversity in their respective characteristics.

\section{References}

Andrews, B., Hejdenberg, J., \& Wilding, J. (2006). Student anxiety and depression: comparison of questionnaire and interview assessments. Journal of Affective Disorders, 95(1), 29-34. https://doi.org/10.1016/j.jad. 2006.05.003

Arco, J. L., Fernandez, F. D., Heilborn, V. A., \& Lopez, S. (2005). Demographic, academic and psychological profile of students attending counseling services at the University of Granada (Spain). International Journal for the Advancement of Counselling, 27(1), 71-85. https://doi.org/10.1007/s10447-005-2249-8

Arnett, J. J. (2000). Emerging adulthood: A theory of development from the late teens through the twenties. American psychologist, 55(5), 469. https://doi.org/10. 1037/0003-066X.55.5.469

Bertocci, D., Hirsch, E., Sommer, W., \& Williams, A. (1992). Student mental health needs: Survey results and implications for service. Journal of American College Health, 41, 3-10. https://doi.org/10.1080/07448481. 1992.9936300

Fiates, G. M. R., \& Salles, R. K. (2001). Fatores de risco para o desenvolvimento de distúrbios alimentares: um estudo em universitárias [Risk factors to the development of eating disorders: a study with university women]. Revista Nutrição, 14, 3-6. https://doi.org/ 10.1590/S1415-52732001000400001

Field, A. (2000). Discovering Statistics Using SPSS for Windows: Advanced Techniques for Beginners. London, UK: Sage Publications.

Gallagher, R.P., Golin, A. \& Kelleher, K. (1992). The personal, career and learning skills needs of college students. Journal of College Student Development 33, 301-309. https://doi.org/10.1007/BF01409602

Gallagher R, Sysko H, \& Zhang B. (2001). National survey of counseling center directors (Series No. 8-K). Alexandria, VA: International Association of Counseling Services.

Giovazolias, T., Leontoponlan, S., \& Triliva, S. (2010). Assessment of Greek university students' counseling needs and attitudes: an exploratory study. International Journal of Advancement of Counseling, 32, 101-116. https://doi.org/10.1007/s10447-010-9092-2

Gysbers, N.C. \& Henderson, P. (2006). Developing and managing your shool guidance program $\left(4^{\text {th }}\right.$ ed.). Alexandria, VA: American Counselling Association.

Gorsuch, G. J. (2003). The educational cultures of international teaching assistants and US universities. Tesl-Ej, 7(3), 1-17.

Güneri, O. Y., Audin, G., Skovhott, T. (2003). Counseling needs of students and evaluation of counseling services at a large urban university in Turkey. International Journal of Advancement of Counseling, 25, 53-63. https://doi.org/10.1023/A:1024928212103

Herreras, E.B. (2002). Diseño y aplicación de un cuestionario de deteción de necesidades de orientación psicológica en un grupo de alumnos/as de la universidad de León en fase piloto [Design and implementation of a needs assessment questionnaire concerning the psychological counselling in a group of students from León University in a pilot phase]. Revista de Psicodidactica, 14, 115-130. http://www.ehu.eus/ojs/ index.php/psicodidactica/article/view/148/144

Hinderaker, D. J. (2013). College Student Mental Health and Use of Counseling Center Services. Master of Social Work Clinical Research Papers. Paper 190. http://sophia.stkate.edu/msw_papers/190

Kenny, M. C., Aluede, O., \& McEachern, A. (2009). A Comparison of Counselling Students' Needs in the United States and Nigeria. Australian Journal of Guidance and Counselling, 19, 41-55. https://doi.org/ 10.1375/ajgc.19.1.41

Kessler, R. C., Berglund, P., Borges, G., Nock, M., \& Wang, P. S. (2005). Trends in suicide ideation, plans, gestures, and attempts in the United States, 1990-1992 to 2001-2003. Jama, 293(20), 2487-2495. https:// doi.org/10.1001/jama.293.20.2487

Kitzrow, M. A. (2003). The mental health needs of today's college students: challenges and recommendations. NASPA Journal, 41(1), 167-181. https://doi.org/10. 2202/0027-6014.1310

Loeffler, D., Haynes, H., Rengel, E., Volk, M., \& Wilkin, D. (1984). 1984 student needs assessment summary. Unpublished Report. University of Minnesota, Student Counseling Bureu.

Marôco, J. (2010). Análise de equações estruturais: Fundamentos teóricos, software \& aplicações [Structural equation analysis: Theoretical fundamentals, software and applications]. Lisbon: ReportNumber, Lda.

Nicholas, L (1995). Personal, career and learning skills needs of first-year university students. International Journal of Advancement of Counseling, 18, 33-37. https://doi.org/10.1007/BF01409602

Nicholas, L. J. (2002). South African first-year student's counseling needs and preferred counseling sources. International Journal of Advancement of Counseling, 24, 289-295. https://doi.org/10.1023/A:1023376930986

Pestana, M. H., \& Gageiro, J. N. (2005). Análise de Dados para Ciências Sociais [Data Analysis for Social Sciences]. 4a Edição. Lisbon: Sílabo.

Pinto, J. C. (2010). Gestão pessoal da carreira: estudo de um modelo de intervenção psicológica com bolseiros de investigação [Career Self-management: study of a psychological intervention model with research grantholders]. Unpublished doctoral thesis. Braga: University of Minho. 
Pérez Campanero, M.P. (1991). Como detectar las necesidades de intervención socioeducativa [How to detect the socioeducational intervention needs]. Madrid: Narcea.

Pinto, J.C., Faria, L., Pinto, H. R., \& Taveira, M. C. (2016). Identificação de Necessidades de Intervenção Psicológica: um estudo piloto no ensino superior português [Identification of psychological needs: a pilot study in the portuguese in higher education]. Psicologia USP. http://hdl.handle.net/10400.14/20851

Rickinson, B. (1998). The relationship between undergraduate student counselling and successful degree completion. Studies in Higher Education, 23(1), 95-102. https://doi.org/10.1080/03075079812331380522

Roberts, R., \& Zelenyanski, C. (2002). Degrees of debt. In N. Stanley \& J. Manthorpe (Eds.), Students' mental health needs: Problems and responses (pp. 107-120). London: Jessica Kinsley.

Rojo, V. A., Jiménez, E. G., Flores, J. G., Clares, P. M. Rodriguéz, S. R. \& Santero, J. R. (2002). Diseño y evaluación de programas [Design and assessment of programs]. Madrid: Editoral EOS.

Setiawan, J. L. (2006). Willingness to seek counselling, and factors that facilitate and inhibit the seeking of counselling in Indonesian undergraduate students. British Journal of Guidance \& Counselling, 34, 403419. https://doi.org/10.1080/03069880600769654

Silva, R. \& Nascimento, I. (2012). Estudantes maiores de 23 anos em Psicologia: Motivações e processo de integração [Students older than 23 years in Psychology: Motivations and integration process]. Revista Brasileira de Orientação Profissional, 13(1), 37-47.

Tahan, M., Tahan, M., Abu-Eitah, S., \& Abu-Eitah, S. (2002). The counseling needs of the Hashemite University students. Dirasat Journal, 29(1), 129-152
Tejedor, F.J. (1990). Perspectiva Metodológica del diagnóstico y evaluación de necesidades en el cambio educativo [Methodological perspective about the diagnosis and assessement of needs in the educational change]. Revista de Investigación Educativa, 8(16), 15-37.

Van Schoor, W. A. \& Whittaker, S. R. (1988). Are we meeting the counseling needs of the students' community? A needs assessment involving students on a South African campus. International Journal of Advancement of Counseling, 11, 127-134. https://doi. org/10.1007/BF00155973

Voitkāne, S., Miezīte, S., Rasčevska, M., \& Vanags, M. (2006). Presentations of Empirical and Theoretical Studies: Student motivation for choice of study program, psychological well-being, perceived social support and needs at the start of university studies. Baltic Journal of Psychology, 7 (1), 46-59. Retrieved from http://www.lu.lv/fileadmin/user_upload/lu_portal/ apgads/PDF/BalticJournPsychol-2006-Vol-7_No-1.pdf

Wagner, G. A., Stempliuk, V. A., Zilberman, M. L., Barroso, L. P., \& Andrade A. G. (2007). Alcohol and drug use among university students: gender differences. Revista Brasileira Psiquiatra, 29, 123-129. https://doi. org/10.1590/S1516-44462006005000033

Weissberg, M., Berentsen, M., Cote, A., Cravey, B., \& Heath, K. (1982). An assessment of the personal, career, and academic needs of undergraduate students. Journal of College Student Personnel, 23,115-122. https://doi. org/10.1207/s15328023top1604_1

Zivin, K., Eisenberg, D., Gollust, S. E., \& Golberstein, E. (2009). Persistence of mental health problems and needs in a college student population. Journal of affective disorders, 117(3), 180-185. https://doi.org/10.1016/j. jad.2009.01.001
Fecha de recepción: 17 de agosto de 2017. Fecha de revisión: 12 de noviembre de 2017. Fecha de aceptación: 14 de noviembre de 2017. Fecha de publicación: 1 de diciembre de 2017. 